\title{
Allo-limbal transplantation in patients with limbal stem cell deficiency
}

\author{
Harminder S Dua, Augusto Azuara-Blanco
}

\begin{abstract}
Aim-To report the outcome of a series of patients with stem cell deficiency who underwent allo-limbal transplantation and to describe a technique for this procedure.

Methods-Six consecutive patients underwent allo-limbal stem cell transplantation. The primary diagnosis included alkali burn $(n=2)$, trachoma $(n=1)$, chronic rosacea blepharitis and keratoconjunctivitis $(n=1)$, aniridia $(n=1)$, and Stevens-Johnson syndrome $(n=1)$. The limbal rim consisted of peripheral cornea and perilimbal sclera. FK-506 was used postoperatively for immunosuppression.

Results-The length of follow up ranged from 3 to 24 months (mean follow up 11.8 (SD 9.3) months). The outcome was considered satisfactory in five of six cases. The corneal surface was completely epithelialised within 2 weeks, and there was a substantial improvement in vision and symptoms. One patient had recurrent epithelial defects related to eyelid abnormalities. No side effects associated with systemic immunosuppression were noted. Conclusion-Allo-limbal transplantation, with systemic immunosuppression with FK-506 is useful in reconstruction of the ocular surface with improvement in vision in patients with severe stem cell deficiency.

(Br f Ophthalmol 1999;83:414-419)
\end{abstract}

Ophthalmology,

Queen's Medical

Centre, University

Hospital, Nottingham

H S Dua

A Azuara-Blanco

Correspondence to:

Professor Harminder S Dua,

B-Floor, South Block,

Queen's Medical Centre.

Nottingham NG7 2UH.

Accepted for publication 22 October 1998
Corneal stem cells are principally located at the sclerocorneal limbus, ${ }^{1}$ and are indispensable for the maintenance of a healthy corneal surface. Loss of limbal stem cells, or corneal stem cell deficiency, can be partial or total. Limbal stem cell deficiency can be associated with persistent epithelial defects, vascularisation of the cornea, conjunctivalisation of the cornea, corneal scarring, melting, ulceration and perforation of the cornea, corneal calcifi- cation, and band keratopathy..$^{2-8}$ The symptoms of limbal deficiency may include decreased vision, photophobia, tearing, blepharospasm, and recurrent episodes of pain, as well as a history of chronic inflammation with redness. Diagnosis of limbal stem cell deficiency is crucial because patients with these abnormalities generally are poor candidates for conventional corneal transplantation. Lamellar or penetrating keratoplasty provides only a temporary replacement of the host's corneal epithelium and does not permanently reconstitute the limbal function. ${ }^{9}{ }^{10}$ In patients with limbal stem cell deficiency, limbal autotransplantation ${ }^{12-19}$ or allotransplantation ${ }^{14-23}$ should be considered for corneal surface reconstruction. This may be combined with or followed by keratoplasty.

Several techniques have been reported for limbal stem cell transplantation. All the procedures share the goal of transplantation of a new source of epithelium for a diseased ocular surface and the removal of the host's altered corneal epithelium and pannus. ${ }^{12-23}$ After successful transplantation the host's cornea (or grafted cornea) will be permanently covered by epithelium from the donor. Although all techniques used in stem cell transplantation are similar in principle the source of donor stem cells can vary. Donor tissue can be obtained from the fellow eye (limbal autograft) in cases of unilateral disease; or from a living related donor or cadaver donor (whole globe or corneoscleral disc) (limbal allograft) when both eyes are affected. Limbal transplantation procedures also vary depending on the carrier tissue used for the transfer of the limbal stem cells. Carrier tissue is needed in limbal transplantation because it is not possible to transfer limbal stem cells alone. Limbal transplants have used either conjunctiva (conjunctival limbal graft) or cornea (keratolimbal graft) as a carrier tissue for limbal stem cells. ${ }^{17}$

This report describes a modified surgical technique for limbal stem cell transplantation and the outcome of a series of consecutive patients undergoing limbal allograft.

Table 1 Demographics and clinical data

\begin{tabular}{|c|c|c|c|c|c|c|c|c|}
\hline $\begin{array}{l}\text { Patient No, } \\
\text { age (years), } \\
\text { sex }\end{array}$ & Eye & Primary diagnosis & Previous surgeries & $\begin{array}{l}\text { VA before } \\
L T\end{array}$ & Surgeries associated & $\begin{array}{l}\text { Follow up } \\
\text { (months) }\end{array}$ & $V A$ after $L T$ & Complications \\
\hline $1,85, \mathrm{~F}$ & $\mathrm{LE}$ & Rosacea & - & $\mathrm{CF}$ & PK, ECCE, PC-IOL & 23 & $6 / 60$ & Glaucoma \\
\hline $2,54, \mathrm{~F}$ & LE & Aniridia & ECCE & $\mathrm{HM}$ & - & 24 & $1 / 60$ & Rejection episode \\
\hline $3,65, M$ & $\mathrm{LE}$ & Trachoma & $\mathrm{PK}(\times 3)$ & HM & PK, ECCE, PC-IOL & 10 & $6 / 12$ & \\
\hline $4,35, M$ & $\mathrm{RE}$ & Alkali burn & AMT & $\mathrm{HM}$ & - & 6 & $6 / 60$ & $\begin{array}{l}\text { Epithelial irregularity } \\
\text { Stromal opacity }\end{array}$ \\
\hline $5,76, M$ & $\mathrm{RE}$ & Alkali burn & Entropion correction & HM & PK, ECCE, PC-IOL & 5 & HM & Epithelial defect \\
\hline $6,31, \mathrm{~F}$ & $\mathrm{RE}$ & Stevens-Johnson & PK & LP & PK, ECCE, PC-IOL & 3 & $6 / 18$ & - \\
\hline
\end{tabular}

$\mathrm{VA}=$ visual acuity; $\mathrm{LT}=$ limbal transplantation; ECCE = extracapsular cataract extraction; PC-IOL = posterior chamber intraocular lens implantation; PK = penetrating keratoplasty; $\mathrm{AMT}=$ amniotic membrane transplantation; $\mathrm{HM}=$ hand movements; $\mathrm{CF}=$ counting fingers. 

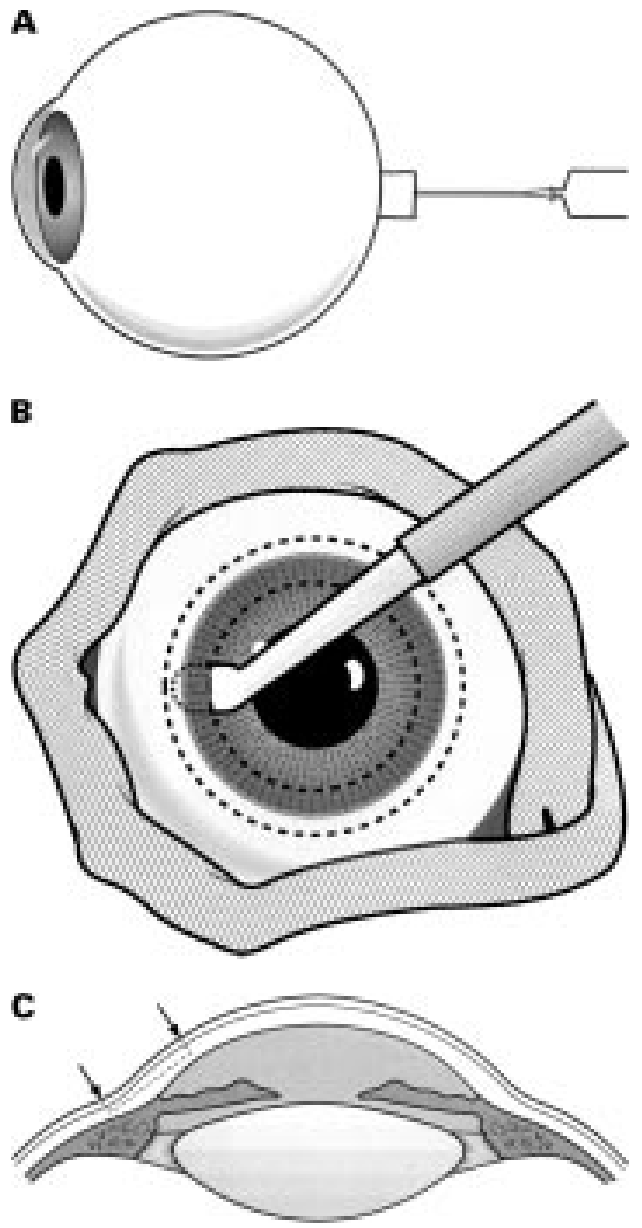

Figure 1 Surgical technique. Harvesting donor limbus. (A) Inflating eyeball with sterile air injected through the optic nerve. This route allows air to remain trapped in the vitreous cavity and keeps the eye firm during tissue dissection. (B) Lamellar dissection of a ring of peripheral cornea, limbus, and adjacent sclera with an angled bevel up blade. The donor eyeball is wrapped with a strip of gauze to facilitate handling. $(C)$ The diagram illustrates the location of tissue dissected.

\section{Materials and methods}

Patients with severe bilateral ocular surface abnormalities were treated by limbal allograft transplantation. The diagnosis of limbal stem cell deficiency was made clinically based on the ocular history, patient observation immediately after chemical injury and close follow up, presence of corneal neovascularisation, staining of epithelial cells on the corneal surface by fluorescein, limbal inflammation, and limbal abnormalities. Six consecutive patients were included in this study. Demographics and diagnosis are summarised in Table 1. All patients had long standing problems except case 4 who underwent limbal allotransplantation 3 weeks after severe alkali burn. This patient had a non-healing epithelial defect affecting the cornea and bulbar conjunctiva, dense stromal opacity, severe limbal ischaemia of two quadrants, and persistent inflammation.

\section{SURGICAL TECHNIQUE}

Preparation of the donor tissue from cadaver eyes "Fresh" donor eyes were preferred because the success of the procedure depends on the transplantation of healthy limbal stem cells. Donor

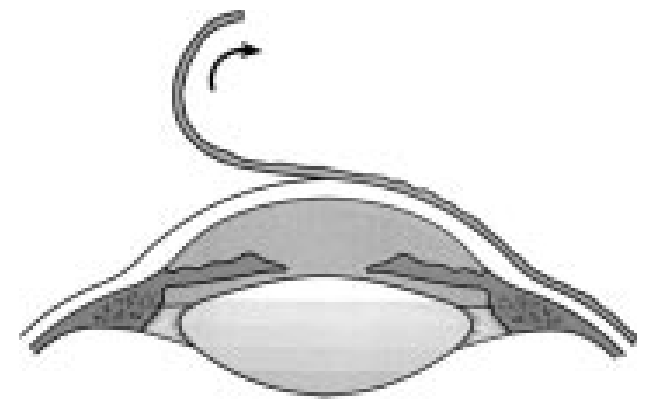

Figure 2 Surgical technique. Preparing the host bed. After a $360^{\circ}$ peritomy, a plane of dissection superficial to corneal stroma is created and the entire fibrovascular membrane is lifted off the surface.

material was taken from eyes enucleated promptly after death and stored for up to 24 hours at $4^{\circ} \mathrm{C}$. Whole eyes were used for two reasons: (1) it allowed for rapid transport of tissue from source centre to our department with processing of tissue required at an eye bank; and (2) it provided better stabilisation of the cornea and sclera during dissection of the limbal sclerocorneal rim. The donor eye was inflated with air (1-2 ml), injected through the stump of the optic nerve, to make the globe firm (Fig 1A). The globe was wrapped around with a strip of wet gauze and held on a Tudor Thomas stand. A vacuum trephine, with a diameter $3 \mathrm{~mm}$ smaller than the corneal diameter (that is, average of vertical and horizontal corneal diameter), was used to trephine the donor central cornea into one fourth to one fifth of the stromal depth (approximately 150 $\mu \mathrm{m})$. Particular attention was paid to proper centration to ensure that a uniform width of peripheral cornea was obtained. Superficial lamellar dissection of the peripheral cornea was then carried out using an angle bevel up blade, and extended into the sclerocorneal junction and $1 \mathrm{~mm}$ beyond, into sclera (Fig 1B and C). Approximately 1-2 $\mathrm{mm}$ of donor conjunctiva, if present, was maintained. The dissected tissue was divided at one point and excision completed with a curved scissors, by cutting along the outer circumference of the dissected tissue. The limbal tissue to be grafted thus consisted of an open ring of peripheral corneal and limbal epithelium (and conjunctival tissue at places), and superficial corneal, limbal, and scleral stroma.

\section{Preparation of the recipient eye}

Good exposure was obtained by opening the lids widely with a speculum, superior and inferior rectus fixation sutures, and a lateral canthotomy (in two cases). A $16 \mathrm{~mm}$ Flieringa ring was sutured in place when the procedure was combined with a corneal graft (and lens extraction with implant). A $360^{\circ}$ peritomy was done, close to the host limbus. The vascularised conjunctiva was recessed about $5-6 \mathrm{~mm}$ to expose the limbus and perilimbal sclera. A superficial keratectomy was done to remove all abnormal epithelium and the superficial fibrovascular scar tissue. This abnormal tissue was stripped off by blunt dissection after a suitable plane was created with a bevel up angle blade 

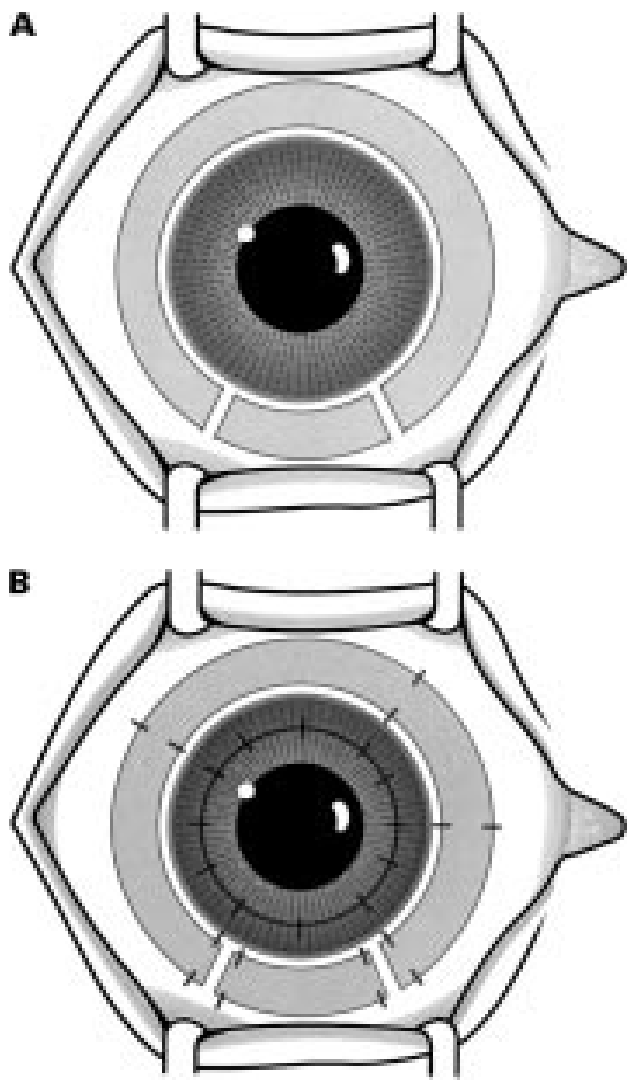

Figure 3 Surgical technique. Transplanting the donor limbal ring. (A) The harvested ring of tissue carrying the "stem cells" is placed around the recipient limbus. A small arc of similar tissue, to fill the gap between the cut ends of the limbal ring, is cut to size and appropriately placed. (B) The limbal explants are sutured along both inner and outer circumferences using 10-0 nylon sutures. The sutures are placed directly opposite to each other. In this illustration a central penetrating keratoplasty is also shown.

(Fig 2). In case 4 there was no pannus covering the host surface.

\section{Limbal transplantation}

The anterior edge of the "open ring" (with donor peripheral corneal tissue + limbus + sclera) was placed at the host limbus (Fig 3A). Therefore, the donor limbus was slightly posterior to the host limbus, increasing the length of the circumference to be covered. The limbal tissue was sutured with interrupted 10-0 nylon sutures at the corneal and scleral margin. Six to eight sutures were first passed along the inner (corneal) edge of the donor tissue and partial thickness of host corneal stroma. A similar number of sutures were then passed directly opposite to the inner sutures, along the outer (scleral) edge of the donor tissue. These were anchored to the superficial sclera of the host. The tension on these sutures also determined the final tension on the inner sutures. The knots were trimmed and buried. This method invariably left a small gap (approximately $5-8 \mathrm{~mm}$ ) between the two ends of the donor tissue ring. This was filled with a "spacer" fashioned out of donor corneal stroma or a piece of donor limbal tissue, cut to size, harvested from the other eye of the same donor. This piece usually required a couple of additional sutures along either edge. The host conjunctiva was approximated to the limbus with interrupted 8-0 Vicryl sutures. When a penetrating keratoplasty was required at the time of surgery the limbal tissue was first sutured in place (Fig 3B). The donor graft for penetrating keratoplasty was obtained from the central cornea of the donor whole globe. Subconjunctival antibiotics and corticosteroids are injected at the end of the procedure. All surgeries were performed by one of the authors (HSD).

\section{Postoperative treatment}

Topical preservative-free chloramphenicol $0.5 \%$ was used four times a day for the first month. Topical preservative-free prednisolone acetate $1 \%$ was used four times a day for the first 12 weeks, and slowly tapered during the next months. A low dose of topical corticosteroids (one drop per day) was maintained unless elevation of intraocular pressure occurred. Preservative-free artificial tears every hour and highly viscous methylcellulose four times daily were initially used and tapered after epithelial healing was completed.

Autologous serum eye drops were prepared and given hourly until the epithelialisation was completed, usually within the first week after surgery. To prepare serum eye drops $50 \mathrm{ml}$ blood were obtained by venepuncture and centrifuged for 5 minutes at $1500 \mathrm{rpm}$. A $20 \%$ solution of serum was then prepared with saline in a sterile environment and placed into sterile vials, each of them containing $5 \mathrm{ml}$ of the solution. The vials were kept frozen in a refrigerator at $-20^{\circ} \mathrm{C}$, and one vial per day was defrosted and used.

Vigorous postoperative immunosuppression with FK-506 was used at least during the first 18 months after surgery. All patients underwent thoracic radiography, blood tests (renal function tests), urine tests, and blood pressure determination before and during FK-506 treatment. The daily total dose was initiated at $0.1-0.2 \mathrm{mg} / \mathrm{kg}$ of body weight per day 1 day before surgery, and continued for at least 1 year, trying to maintain the trough level between 3 and $15 \mathrm{ng} / \mathrm{ml}$. The serum levels and patient's systemic condition (blood pressure, thoracic radiography, blood tests (renal function tests: SMA-12), and urine tests) were checked every week for the first month and every 2-4 weeks later. The FK-506 dosage was increased or decreased if it proved ineffective or caused adverse effects.

\section{Results}

The length of follow up ranged from 3 to 24 months, with an average follow up of 11.8 (SD 9.3) months. Histological examination of the host's corneal pannus confirmed the presence of conjunctival-like epithelium. Postoperatively, in all cases, outgrowths of epithelial sheets from the limbal grafts started within the first 3 days and the whole corneal surface was completely epithelialised within 2 weeks (Fig 4). There was no infection, limbal graft failure, or slippage of tissue. The epithelium was stable in five of six patients (that is, there were no recurrence of epithelial defect, see Figs 5 and 

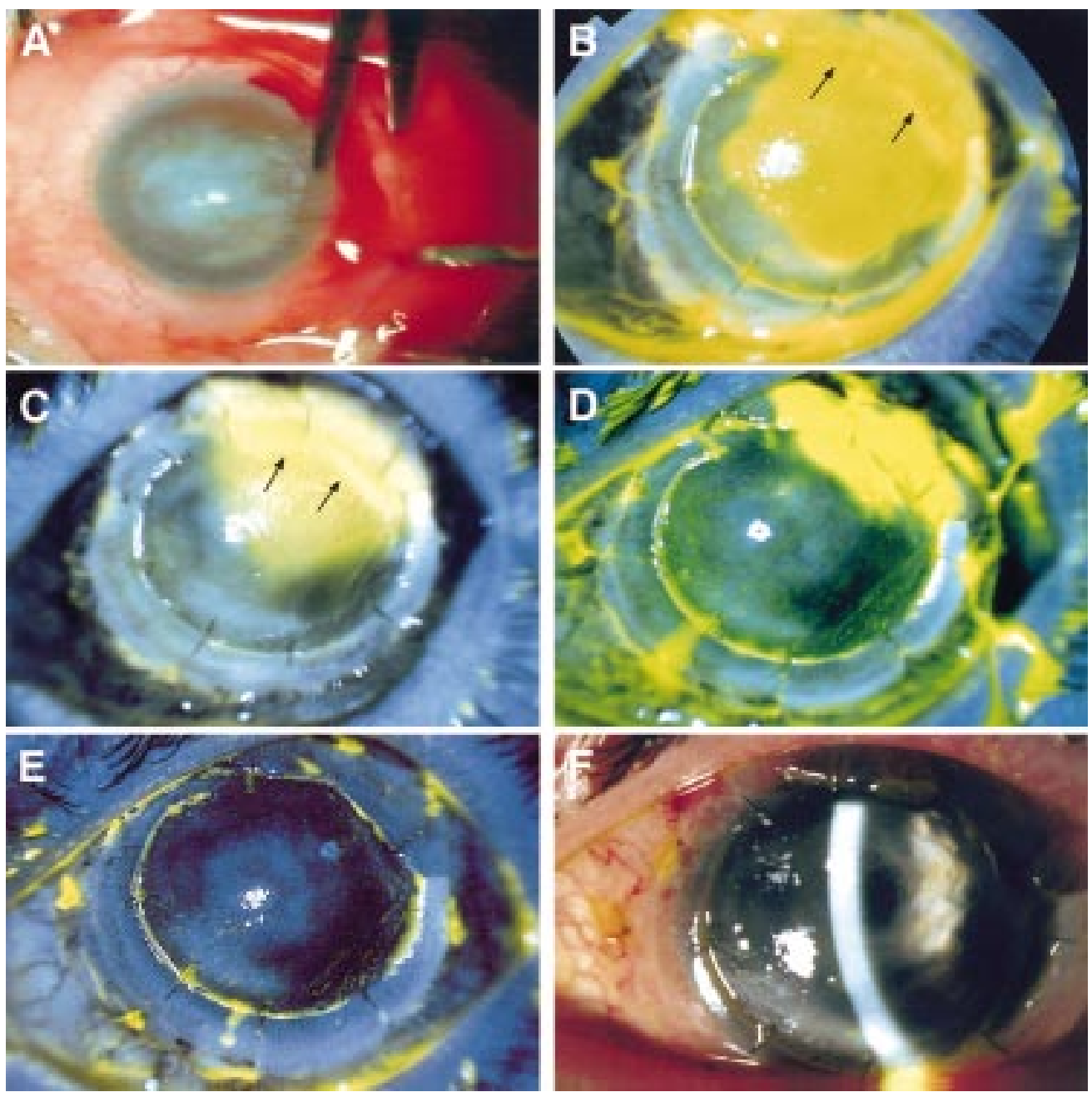

Figure 4 Results of limbal transplant in case 2 (primary diagnosis: aniridia). (A) The external appearance of the right eye showing an extensive fibrovascular membrane covering the cornea. The picture was taken during surgery while a peritomy was being done. (B) Slit lamp photograph (fluorescein stained) of the same eye 3 days after surgery. Corneal epithelial cells have started to migrate from the transplanted limbus and are migrating across the host cornea. The quadrant indicated with arrows, where no epithelial cell migration is seen, corresponds to the site where a spacer, fashioned from corneal collagen (without epithelial cover), was placed. (C) Slit lamp photograph (fluorescein stained) of the same eye, 5 days after surgery. Three quarters of the host surface is re-epithelialised. The quadrant corresponding to the spacer (arrows) has remained bare. (D) Slit lamp photograph (fluorescein stained) of the same eye, 7 days after surgery. The remaining quadrant is almost covered by cells migrating from the other quadrants. (E) Slit lamp photograph (fluorescein stained) of the same eye taken on day 8 post surgery. Re-epithelialisation of the host corneal surface from donor limbus is complete. $(F)$ Slit lamp photograph of the same eye 6 weeks after surgery. The cornea is clear and the surface is smooth as illustrated by the broad slit beam. Remnants of the lens capsule (following needling for congenital cataract) with a central opening are now clearly visible.

6), transparent and smooth (in four of six cases). In case 4 the corneal epithelium was irregular, which was attributed to previous stromal abnormalities and persistent low grade inflammation; stromal melting did not occur, and a penetrating keratoplasty was done 5 months after limbal transplantation. Visual acuity improved in five of six patients, and was very substantial in two of them (cases 3 and 6). Improvement of visual function was only moderate in cases 1,2 , and 4 because of pre-existing abnormalities (see Table 1). Case 5 had a satisfactory reconstruction of the corneal epithelial surface and vision improved to $6 / 60$ shortly after surgery. However, the follow up was complicated with several episodes of epithelial defects associated with eyelid abnormalities. This corneal epithelium could be restored but stromal opacity developed and a repeated corneal graft was done 4 months after limbal transplantation.
Side effects related to FK-506 were not observed. All cases but two (cases 1 and 2) were still taking FK-506 at the time of submission of this paper. In case 1, FK-506 was discontinued 13 months after surgery. He presented with a rejection episode of the limbal graft (intense congestion along scleral edge, oedema of donor tissue, and clouding of tissue) and of the corneal graft (keratic precipitates and stromal oedema) 2 months later. FK-506 orally and topical steroids were recommenced. The rejection settled with complete clearing of limbal and corneal graft tissue. FK-506 was finally discontinued 5 months later. Case 2 had limbal allograft rejection 4 months after surgery, with engorgement of limbal and conjunctival vessels, and the dosage of FK-506 was increased. Three weeks later the vascular engorgement regressed. In this patient immunosuppression was discontinued 18 months 

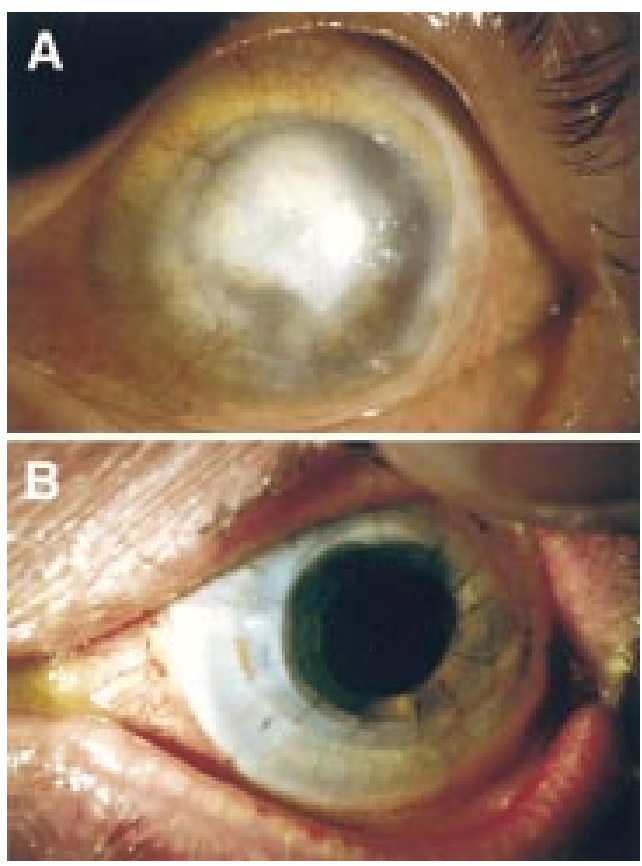

Figure 5 Results of combined limbal and corneal transplant with lens extraction and implant (quadruple procedure) in case 3. (A) Preoperative picture of the left eye of a patient with clinical diagnosis of trachoma of 30 years' duration. The cornea is scarred and vascularised with calcium deposition. The outline of a previously failed corneal graft is visible. Preoperative vision was hand movements. (B) The same eye 8 weeks after surgery. The patient has a follow up of 9 months and maintains a vision of 6/12 unaided and 6/9 with a pinhole.
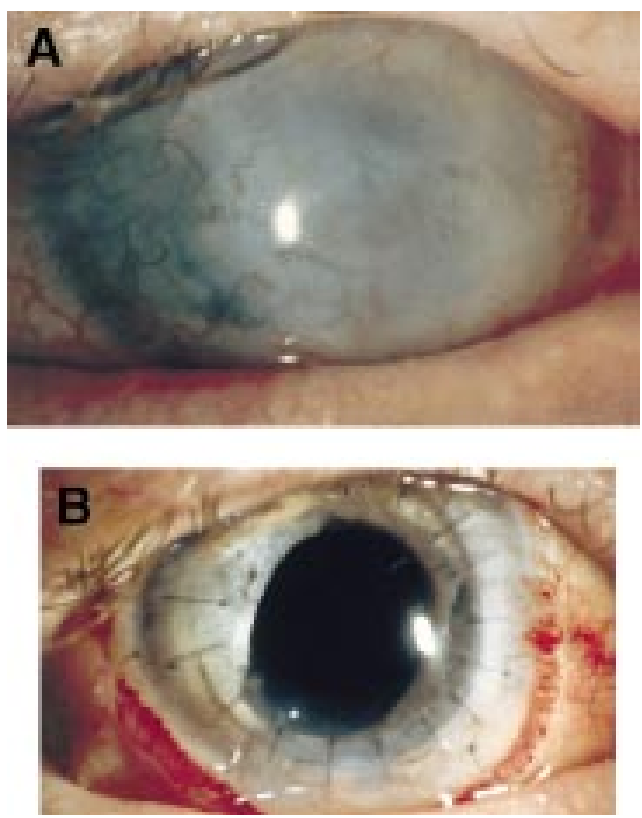

Figure 6 Results of combined limbal and corneal transplant with lens extraction and implant (quadruple procedure) in case 6. (A) Preoperative picture of the right eye of a patient with clinical diagnosis of Stevens-Fohnson syndrome. The cornea is scarred and vascularised.

Preoperative vision was light perception. (B) The same eye 4 weeks after surgery.

after surgery and 6 months later graft rejection did not recur.

\section{Discussion}

The aetiology of limbal stem cell deficiency can be primary - related to an insufficient stromal microenvironment to support stem cell functions, such as aniridia, congenital erithrokeratodermia, keratitis associated with multiple endocrine deficiencies, neurotrophic (neural and ischaemic) keratopathy, and chronic limbitis, or secondary - related to external factors that destroys the limbal stem cells such as chemical or thermal injuries, Stevens-Johnson syndrome, ocular rosacea, ocular cicatricial pemphigoid, multiple surgeries or cryotherapies, contact lens wear, or extensive microbial infection. ${ }^{24}$ In this series most patients (five of six) had secondary limbal stem cell deficiency.

The technique described in this article was a variation of previously described limbal transplantation. ${ }^{20}{ }^{21}$ In 1984, Thoft used lenticules of peripheral cornea from a cadaveric donor globe as a source of epithelium (that is, keratoepithelioplasty) but limbal cells were not transplanted. ${ }^{25}$ The first trials of human limbal stem cell transplant were performed by Kenyon and Tseng in 1989 through limbal autograft transplantation to treat unilateral ocular surface disorders. ${ }^{11}$ They transplanted conjunctiva and limbus presumably including stem cells, from the good fellow eye to the recipient eye. Since this original report several variations of limbal autografts ${ }^{12-19} 2627$ and allografts ${ }^{14-23} 28$ have been reported with good reconstitution of the corneal epithelium and regression of neovascularisation. Cornea or conjunctiva have been the most commonly used carriers to transplant limbal stem cells. In this study peripheral cornea, perilimbal sclera, and conjunctiva were used as carriers for limbal cells and providers of an adequate microenvironment for their survival and replication. After surgery, autologous serum eye drops were used as described by other authors to promote corneal epithelialisation. ${ }^{20}$

We performed six limbal allograft transplants to reconstruct corneal surface severely affected by different disorders. All patients had very poor vision and were not manageable with penetrating keratoplasty alone. All cases achieved rapid surface healing restoration of an optically improved surface, resulting in improved visual acuity. In five of six patients visual function improved. However, two patients required penetrating keratoplasty after limbal transplantation for visual rehabilitation. In limbal allografts the surface disorder can recur if there is immunological destruction of the transplanted limbal stem cells. A high rate of immune reactions can be expected because the high immunogenic stimulus of the limbal transplant, related to the relatively abundant of Langerhans cells and HLA-DR antigens. ${ }^{29}$ They play an important role in the afferent arm of allograft rejection and effective immunosuppression is judged to be absolutely necessary. Several authors had used cyclosporine A as the immunosuppressive agent. ${ }^{16202123}$ The use of FK-506, a new agent isolated from the fermentation broth of Streptomyces tsukubaensis, for immunosuppression in limbal or corneal allografts has not been reported before. FK-506 has been successfully used in organ transplantation $^{30}$ and uveitis. ${ }^{31-33}$ This agent has immunosuppressive activities similar to and 
more potent than those of cyclosporine. ${ }^{34} 35$ The major side effects of FK-506 are sensation of warmth, hypomagnesaemia, renal dysfunction, glucose intolerance, nausea, vomiting, and disorders of the central nervous system. In this series FK-506 was well tolerated by all patients. One patient had an episode of rejection that could be controlled by increasing the dosage of the drug. Limbal rejection can be suspected with the development of inflammation and/or acute or chronic severe surface disorders. ${ }^{20}$ Our decision to stop this drug months after surgery was empirical. It is not known whether immunosuppression may not be necessary in some patients undergoing allolimbal transplantation. Hypothetically, patients receiving HLA matched limbal tissue may not need intense immunosuppression. Tan et al reported three cases who received limbal tissue from living relatives without systemic immunosuppression and no rejection was noted after midterm follow up. ${ }^{19}$ The duration of systemic immunosuppression in allo-limbal transplantation is yet undefined. Some authors advocate indefinite oral cyclosporine treatment. ${ }^{23}$ In this series, two patients discontinued FK-506. One of them developed a rejection episode which was controlled, FK-506 was again stopped, and rejection did not recur. Longer follow up and further research is necessary to evaluate whether FK-506 can be stopped, its timing, and the long term outcome of limbal transplantation.

In conclusion, allo-limbal transplantation with corneal, scleral, and conjunctival carriers for ocular surface reconstruction, associated with systemic FK-506 immunosuppression, has a successful midterm outcome and is a valuable option for patients with severe bilateral limbal stem cell deficiency.

Dr Azuara-Blanco is the current Vision Express fellow in cornea and contact lenses.

We are grateful to Dr Richard J Powell and Mrs Myra Sloper for monitoring our patients on FK-506.

1 Schermer A, Galvin S, Sun TT. Differentiation-related expression of a major $64 \mathrm{~K}$ corneal keratin in vivo and in
culture suggests limbal location of corneal epithelial stem culture suggests limbal location

2 Chen JJY, Tseng SCG. Corneal epithelial wound healing in partial limbal deficiency. Invest Ophthalmol Vis Sci 1990;31: 1301-14

3 Huang AJW, Tseng SCG. Corneal epithelial wound healing in the absence of limbal epithelium. Invest Ophthalmol Vi Sci 1991;32:96-105.

4 Kenyon KR, Bulusoglu G, Ziske JD. Clinical pathologic correlations of limbal autograft transplantation. Am f Oph thalmol 1990;31:1.

5 Kinoshita S, Kiorpes T, Friend J, et al. Limbal epithelium in ocular surface wound healing. Invest Ophthalmol Vis Sci 1982;23:73-80.

6 Kruse FE. Stem cells and corneal epithelial regeneration. Eye 1994;8:170-83.

7 Nishida K, Kinoshita S, Ohashi Y, et al. Ocular surface abnormalities in aniridia. Am F Ophthalmol 1995;120:36875 .
8 Tseng SCG. Concept and application of limbal stem cells. Eye 1989;57:201-9.

9 Brown SI, Bloomfield SE, Pearce DB. Follow-up report on transplantation of the alkali burned cornea. Am $\mathcal{F}$ Ophthalmol 1974;77:538-42.

10 Abel R Jr, Binder PS, Pilack FM, et al. The results of penetrating keratoplasty after chemical burns. Trans $\mathrm{Am}$ Acad Ophthalmol Otolaryngol 1975;79:584-95.

11 Kenyon KR, Tseng SCG. Limbal autograft transplantation for ocular surface disorders. Ophthalmology 1989;96:709-

12 Copeland RA, Char DH. Limbal autograft reconstruction after conjunctival squamous cell carcinoma. Am $\mathcal{F}$ Ophthalmol 1990;110:412-15.

13 Jenkins C, Tuft S, Liu C, et al. Limbal transplantation in the management of chronic contact-lens associated epitheliopathy. Eye 1993;7:629-33.

14 Pfister R. Corneal stem cell disease: concepts, categorization, and treatment by auto- and homotransplantation of limbal stem cells. CLAO f 1994;20:64-72.

15 Kwitko S, Marinho D, Barcaro S, et al. Allograft conjunctial transplantation for bilateral ocular surface disorders. Ophthalmology 1995;102:1020-5

16 Kenyon KR, Rapoza PA. Limbal allograft transplantation for ocular surface disorders. Ophthalmology 1995;102 (suppl):101-2.

17 Holland EJ. Epithelial transplantation for the management of severe ocular surface disease. Trans Am Ophthalmol Soc 1996;94:677-743.

18 Holland EJ, Schwartz GS. The evolution of epithelial transplantation for severe ocular surface disease and a proposed classification system. Cornea 1996;15:549-56.

19 Tan DTH, Ficker LA, Buckley RJ. Limbal transplantation. Ophthalmology 1996;103:29-36.

20 Tsai RJF, Tseng SCG. Human allograft limbal transplantation for corneal surface reconstruction. Cornea 1994;13: 389-400.

21 Tsubota K, Toda I, Saito H, et al. Reconstruction of the corneal epithelium by limbal allograft transplantation for severe ocular surface disorders. Ophthalmology 1995;102: 1486-96.

22 Sundmacher R, Reinhard T. Central corneolimbal transplantation under systemic ciclosporin A cover for severe limbal stem cell insuficiency. Graefes Arch Clin Exp Ophthalmol 1996;234 (suppl):s122-5.

23 Tseng S, Prabhasawat P, Barton K, et al. Amniotic membrane transplantation with or wihout limbal allografts for corneal surface reconstruction in patients with limbal stem cell deficiency. Arch Ophthalmol 1998;116:431-41.

24 Puangsricharen V, Tseng SCG. Cytologic evidence of corneal diseases with limbal stem cell deficiency. Ophthalmology 1995;102:1476-85.

25 Thoft RA. Keratoepithelioplasty. Am f Ophthalmol 1984;97: $1-6$.

26 Clinch TE, Goins KM, Cobo LM. Treatment of contact lens-related ocular surface disorders with autologous conjunctival transplantation. Ophthalmology 1992;99:6348.

27 Mahima Y, Yamada M, Yamada H, et al. Limbal autograft transplantations for chronic ocular surface failures. $\mathcal{F} p n \mathcal{F}$ Clin Ophthalmol 1993;47:607.

28 Turgeon PW, Neuheim RC, Roat MI, et al. Indications for keratoepithelioplasty. Arch Ophthalmol 1990;108:233-6.

29 Pels E, Gaag R van der. HLA-A, B, C and HLA-DR antigens and dendritic cells in fresh and organ culture preserved corneas. Cornea 1984/5;3:231-9.

30 Starzl TE, Todo S, Fung J, et al. FK506 for liver, kidney and pancreas transplantation. Lancet 1990;2:1000-4

31 Sloper CML, Dua HS, Powell RJ. The role of Tacrolimus (FK506) in the treatment of posterior uveitis refectory to cyclosporin A. Ocular Immunology and Inflammation 1997;5(suppl):99.

32 Ishioka M, Ohno S, Nakamura S, et al. FK506 treatment of noninfectious uveitis. Am 7 Ophthalmol 1994;118:723-9.

33 Mochizuki M, Masuda K, Sakane T, et al. A clinical trial of FK506 in refractory uveitis. Am f Ophthalmol 1993;115: 763-9.

34 Kino T, Hatanabe H, Hashimoto M, et al. FK506, a novel immunosuppressant isolated from a streptomyces. I. Fermentation, isolation, and physio-chemical and biological characteristics. F Antibiot 1987;40: 1249-55.

35 Tocci MJ, Matkovich DA, Collier KA, et al. The immunosuppressant FK506 selectively inhibits expression of early T cell activation genes. F Immunol 1989;143:71826. 